\title{
Women, Violence and the Internet
}

\author{
PAMELA M. CLAYTON \\ University of Glasgow, United Kingdom
}

\begin{abstract}
This article explores a hypothesis that the Internet and the World Wide Web form an alternative resource to that provided by conventional adult education providers. The example used is the dissemination and transfer of information on and analysis of issues concerning women and violence. Four important issues for adult (that is, post-compulsory) education are choice, appropriateness and quality of provision, access and participation, and the wider benefits of learning, including the social. This article raises these issues through giving an overview of the use made by women of the Internet, with specific reference to women and violence, based on an analysis of web pages in the English language and registered on the Google search engine.
\end{abstract}

\section{Methodology}

The research was carried out for a colloquium organised by the University Paris 8 in 2001 (Clayton, 2002) and updated in 2007.[1]

A Google search in late 2001, using the term 'women and the Internet', yielded some 19,700 pages, of which 2,000 pages were displayed. The first hundred were analysed numerically, with respect to the types of organisation hosting the pages, the main issues in the web pages, the types of content, regions and types of women focused on. 'Violence against women' yielded around $1,170,000$ pages (873 displayed) and 'women', 'sex' and 'violence' around 746,000 (888 displayed). From these two categories 1,518 pages were subjected to a qualitative analysis, including hosting organisations, the main issues covered, types of content, target audience and countries and regions.

A French language search of 'violence contre les femmes' yielded only 3,520 pages (669 displayed). These were principally from Canada, international organisations such as the United Nations and the French sections of global .org sites, and from France, Belgium, Switzerland, Morocco, Mauritania and other francophone African countries. Since they broadly mirrored the English language search, they were not analysed for the purposes of this article.

The links suggested in the footnotes are meant to show something of the range of sites rather than constituting a representative selection. Those shown as [no longer functional] have disappeared or changed since the original research.

\section{Women and the Internet}

By 1985 the Internet was already well established, allowing communities of researchers to communicate and share ideas. Electronic mail (email) was also being used between communities. By 1986 protocols had been developed which could be used by all computer networks and these were dominant by 1990 . All computers could now, potentially, be linked.

It was already possible to search for information via the Internet, but not particularly easy. The World Wide Web did not take off until 1993. By then there were additional protocols (hypertext transfer protocol [HTTP]), a common language (hypertext mark-up language [HTML]) and the first browser (Mosaic) that could display images as well as text. Today HTTP is the mostused protocol on the Internet, which reflects the use of the World Wide Web and its function of sharing information. The free provision of web browsers like Opera, Netscape, Firefox and 
Explorer, together with a range of search engines, give to anyone who can access a networked computer the freedom to search for information anywhere in the world.

The principal users of the Web and of information technology in general were originally men. It was probably only two years after the take-off of the Web that an initiative was taken to involve women. The Beijing Fourth World Conference on Women in 1995 had a website and email facility which allowed women all over the world to learn what was happening at the conference and to add their own comments and experiences. Although networked computers were not nearly as common then as they are now, the experiment was a great success at the time, and since then the Internet has been a powerful resource for women to learn about other women, exchange views, form virtual communities and so on.

An analysis of the first hundred pages of the 19,700 generated by the Google search of 'women and the Internet' indicates to some extent women's relationship to the Internet. The majority (56) of the pages were both by women (in some cases, a woman) and primarily or entirely for women. Those aimed at women included:

1. 23 pages about women, including statistics on women's Internet use of particular interest to etailers (that is, Internet retailers) and advertisers;

2. 9 pages for women by men or by commercial organisations like search engine providers;

3. 5 pages for American men and women from other parts of the world, seeking romance and marriage;

4. 2 pages aimed at women (the United States Department of Labor Women's Bureau site 'developed to encourage more young women to pursue careers in math, science and technology', and an advertisement for a book on online resources for women);

5. 3 pages containing gendered analyses of Internet use.

The first question concerns women's access to the Internet. We would expect the greatest proportion of Internet users where access to the Internet is relatively easy and where women are more likely to have the education and the financial resources to go online. It was estimated in September 2002 that out of 605.6 million people online, Canada and the USA accounted for 182.67 million, a number disproportionate to their population size.[2] It is not surprising, then, that the majority (69) of pages emanated from the USA.[3] Women in the United States, in particular, were fast increasing their rate of Internet use and were projected to equal the Internet use of men in the very near future. Since 'women control the majority of consumer purchasing dollars', online commercial companies were advised to target women.[4]

The figure for Africa was only 6.31 million and, despite the absence of credible statistics [5], it is a fair assumption that most of these would be men. In 2001 there were African women online and the female educated African élite does have the potential to share the knowledge they derive via the Internet [6] with women without such access, especially in the cities, but access to potentially useful resources remains a problem for many women in the world, and not only in Africa. Even where access is possible, participation by women is likely to be less than that by men given the greater burden of work placed upon women (United Nations Conference on Trade and Development [UNCTAD], 2002, p. 23).

A second issue concerns quality. This was generally impressive. Looking first at the 56 pages by and for women, 33 were guides to online resources of interest to women and search engines for women's issues. Some of these were for women in general, others for more specialised interest groups, such as female biologists and historians, women in science, computing and business, scholars and students of women's studies, history and culture.[7] Other pages included academic articles on women and the Internet [8]; awards to women Internet entrepreneurs and website owners; a campaign to give women 'a voice in cyberspace' [9]; and campaigns using the Internet for the benefit of women.[10] Higher education institutions (HEIs) provided 27 of the 56 pages by and for women, non-governmental organisations (NGOs) 18, commercial organisations 9 and individuals 2. Of the 9 pages for women but not by women, 7 were guides to online resources, provided by an HEI, 3 NGOs and 3 commercial sites.

Finally, what kind of women were the focus of these hundred pages? There were 11 pages directed at women in computing and Internet careers, 7 for women in the scientific field, 6 for those interested in women's studies and 5 for students of other (non-scientific) subjects. There were other specialist pages too - but the largest number, 29, were on the subject of women who use the 
Internet, followed closely by 27 pages aimed at general female Internet users. In other words, the Internet was becoming a space for women in general, whether they were academics, in other occupations or in the home.

The increasing use by women of the Internet, albeit slow and patchy in the world context, enhances the potential of the medium to deal with specific issues such as women and violence and to reach at least some women who have been or are themselves subject to violence and abuse. Accordingly, the next section analyses searches on this subject.

\section{The Internet, Women and Violence}

Specialised searches yielded the following:

1. 'violence against women' yielded around 1,170,000 entries;

2. 'women + sex + violence' yielded around 746,000 entries.

The growth of pornography, including sites that portray actual violence against women for the gratification of subscribers, constitutes a decidedly women-unfriendly aspect of the Internet. Since it is claimed that a substantial amount of traffic on the Internet is devoted to the search for pornography, I was concerned when I began my search that I would come across such sites.

\begin{tabular}{lc}
\hline Type of organisation & No. of \\
& pages \\
\hline Institutions of higher education & 24 \\
Networks, campaigning organisations and resource sites on & 15 \\
women's issues, violence against women and domestic violence & \\
Local women's organisations & 9 \\
Central and local government departments, ministries, etc. & 13 \\
European Union & 1 \\
United Nations and its agencies & 6 \\
Political party (ANC, South Africa) & 1 \\
Online local newspaper & 1 \\
Specialist online magazines/journals not specialising in women & 4 \\
Online sections of mass media organisation (Netherlands) & 4 \\
Medical and health sites & 3 \\
Miscellaneous NGOs and voluntary organisations: & 12 \\
computer users & 4 \\
social development & 1 \\
violence policy & 2 \\
human rights & 1 \\
media and society & 1 \\
professional association & 1 \\
city literacy movement & 1 \\
action for Africa & 1 \\
Commercial sites: & 1 \\
Islamic information and products & 1 \\
book search & 1 \\
football league & 1 \\
Personal sites: & 3 \\
on women and violence & 1 \\
on the arts & 1 \\
Page could not be found & 1 \\
Total & 2 \\
\hline & 1 \\
& 1 \\
\hline
\end{tabular}

Table I. Types of organisation hosting the web pages.

In fact, Google.com, in common with other mainstream search engines, has a policy of focusing on 'respectable' sites, that is, non-pornographic sites, and these appear first in the list. Furthermore, although the search engine lists the total number of entries, it does not list every entry: only a small proportion of total sites are listed. Hence, it was only at the very end of the searches that entries for sites that were clearly pornographic appeared. In search 1, 'violence against women', all but one of 
the first 793 entries were non-pornographic; in search 2, 'women + sex + violence', the first 725 entries were non-pornographic. Fortunately, such sites do not attempt to lure the unwary - it is very obvious what they are and it would be difficult to access one by accident. In my analysis, therefore, of web pages involving women and violence, I focus solely on the non-pornographic pages. In a few cases (2) the same page was on different sites or in two different places on the same site, but the majority were unique instances.

A numerical analysis of the first hundred pages of the first search (women + violence) yielded the information concerning the types of organisation behind the web page, the main issues, the types of content, the types of women who were the main subjects and the regions on which the pages focused (sometimes but not always coterminous with the women who were the subject of the page). Table I lists the types of organisation that hosted the web pages. Given their access to the Internet, it is not surprising that about a quarter of these sites were HEIs and a further $20 \%$ were state and international organisation sites. It is more interesting to note that nearly a quarter were sites set up for women and on women's issues, and 28 were sites which did not specialise in the issues of women and violence but which included them. Table II shows the main issues addressed in the web pages.

\begin{tabular}{lc}
\hline Main issue & $\begin{array}{c}\text { No. of } \\
\text { pages }\end{array}$ \\
\hline Violence against women, general & 58 \\
Violence against women, domestic & 14 \\
Violence against women, rape & 10 \\
Violence both by and against women & 7 \\
Violence by women & 3 \\
Women against violence & 3 \\
Trafficking of women & 2 \\
Women in prison & 1 \\
Page could not be found & 2 \\
Total & 100 \\
\hline
\end{tabular}

Table II. Main issues in the web pages.

Most commonly, pages addressed the issue of violence against women in a general way, with few focusing on just one type of violence, such as domestic violence or rape. Very few dealt with violence committed by women, and two of the three that did explained this as the result of earlier abuse by men. Table III lists the types of content found in the web pages.

\begin{tabular}{lc}
\hline Type of content & $\begin{array}{c}\text { No. of } \\
\text { pages }\end{array}$ \\
\hline Publicity and information on issues, policy, law and & 34 \\
organisations & 27 \\
Analyses of violence against women, including articles, & \\
seminars and conference papers & 7 \\
Campaigns and calls to action & 6 \\
Book reviews & 5 \\
Internet discussion groups & 4 \\
Curricula and study programmes & 3 \\
Bibliographies and databases & 3 \\
News items and editorials & 2 \\
News database & 2 \\
Statistics & 2 \\
Official reports & 2 \\
Accounts of specific instances of violence against women & 1 \\
Conferences & 2 \\
Page could not be found & 100 \\
Total & \\
\hline
\end{tabular}

Table III. Types of content of the web pages. 
It is here that the educational potential of the Web becomes apparent. The majority (80) of pages consisted of information, analysis, book reviews, bibliographies, women's study programmes, statistics, official reports and so on. Even if we allow that this kind of page is prioritised by the search engine, and later pages might well contain 'lighter' (and also less respectable) material, the first pages with which the searcher was presented were overwhelmingly educational.

Table IV lists the regions in which the web pages were hosted or about which they were concerned. Half the pages were either hosted in North America or dealt specifically with women in North America. On the other hand, the wide spread of other countries listed shows that the issue of women and violence was seen as relevant in all continents.

\begin{tabular}{|c|c|}
\hline $\begin{array}{l}\text { Region of site location or } \\
\text { women in question }\end{array}$ & $\begin{array}{l}\text { No. of } \\
\text { pages }\end{array}$ \\
\hline United States of America & 37 \\
\hline Canada & 13 \\
\hline Europe & 16 \\
\hline United Kingdom & 7 \\
\hline Europe as a whole & 3 \\
\hline Balkans & 2 \\
\hline East and Central Europe & 2 \\
\hline France & 1 \\
\hline Netherlands & 1 \\
\hline Australia & 5 \\
\hline South Asia & 9 \\
\hline India & 4 \\
\hline Nepal & 2 \\
\hline Pakistan & 1 \\
\hline Bangladesh & 1 \\
\hline Bhutan & 1 \\
\hline South America & 3 \\
\hline Nicaragua & 1 \\
\hline Peru & 1 \\
\hline Brazil & 1 \\
\hline Africa & 4 \\
\hline South Africa & 3 \\
\hline Senegal & 1 \\
\hline Middle East & 2 \\
\hline Palestine & 1 \\
\hline Kurdistan & 1 \\
\hline Far East & 2 \\
\hline Myanmar & 1 \\
\hline Papua New Guinea & 1 \\
\hline 'Third World' & 1 \\
\hline Page could not be found & 2 \\
\hline
\end{tabular}

Table IV. Regions of the women in question (total is greater than 100 because of multiple references on some pages).

Table V shows the types of women who were the subject of the web pages.

Finally, although some pages were about women in particular situations, the majority took the view, either explicitly or implicitly, that women in general were prone to violent treatment, principally by men. What follows, however, is principally a broadly categorical analysis of 1,518 pages taken from the 'violence against women and women + sex + violence searches. Following the format of the numerical analysis above, I have looked at types of organisation; main issues; types of content (actions and reports of actions, and information and analysis); women targeted by the websites; and regions/countries covered. This presented some difficulties since categories can easily overlap. 


\begin{tabular}{lc}
\hline Types of women & $\begin{array}{c}\text { No. of } \\
\text { pages }\end{array}$ \\
\hline Women in general & 83 \\
Women in war zones & 3 \\
Women in shelters & 2 \\
Afro-American women & 2 \\
Muslim women & 1 \\
Refugees & 1 \\
Students & 1 \\
Health care workers & 1 \\
Violent women & 2 \\
Migrant workers & 1 \\
Rural women & 1 \\
Page could not be found & 2 \\
Total & 100 \\
\hline
\end{tabular}

Table V. Typology of women who were the main subject of each web page.

\section{Organisations that Published on the Internet on Women and Violence}

Providers of web-based information included the following:

- Official organisations and services:

- local (e.g. local government) [11];

- national (e.g. central government, such as the US Department of Justice);

- international (e.g. World Health Organisation [12], United Nations, UNICEF, the United Nations

Commission on Human Rights, the World Bank); and

- transnational organisations (e.g. European Union, Council of Europe) [13];

- Non-state organisations, including:

- churches;

- campaigning bodies, e.g. National Organisation for Women [14], Women Against Violence [15], International Nursing Network on Violence against Women [16], Amnesty International [17];

- women lawyers' groups [18];

- women's refuges and local organisations supporting women victims of violence [19];

- rape crisis centres;

- providers of information for women at risk of violence;

- portal sites for women at risk of violence or wishing for information on violence against women [20];

- organisations of men against sexism and violence against women;

- organisations of men and women against domestic violence;

- broadcasting services (e.g. CNN);

- universities and other academic institutions.[21]

\section{Main Issues}

The content of provision can be divided into general; violence by men against women; violence by women against women; violence by women against men.

\section{General}

- the law and violence against women [22];

- violence against women on the screen, in the media, in computer games, in rap music and on the Internet [23];

- effect of pornography on violence against women;

- women's role or potential role in opposing violence. 
Women, Violence and the Internet

Violence by Men against Women

- domestic violence [24];

- domestic violence as a cause of homelessness for women and children;

- date rape/violence;

- violence against women with disabilities;

- violence against pregnant women;

- violence/gang rape against ethnic minority or low-status women;

- women victims of incest;

- violence and its impact on health, including reproductive health;

- violence and HIV;

- trafficking;

- sex tourism.

\section{Violence by Women against Women}

- lesbians battered by their partners [25];

- female infanticide;

- genital mutilation;

- dowry-related violence.[26]

\section{Violence by Women against Men}

- violence by women, including domestic violence.

\section{Types of Content}

The kinds of resources available include official documents; actions and reports of actions; and information and analysis.

\section{Official}

- official policy statements [27];

- laws and programmes to combat violence against women.

\section{Actions and Reports of Actions}

- virtual communities, message boards, chat rooms [28];

- campaigns for legal redress for women [29];

- publicity for and reports of protest marches and demonstrations;

- publicity for refuges, rape crisis centres, counselling services, therapies, training [30].

- fact sheets, newsletters [31].

- women against gun violence [32];

- manuals, educational videos, referral sheets.

\section{Information and Analysis}

- survivor stories;

- literature (fiction and non-fiction);

- book and film reviews and bibliographies;

- academic studies, including sociological explanations for and historical studies of violence against women [33], and women, violence and the law [34];

- bibliographies, Internet resources; 
- study programmes, courses, curricula;

- reports of conferences and seminars;

- statistics [35];

- studies of women who are themselves violent, including those who commit domestic violence.

\section{Women Targeted by or the Subject of the Websites}

There is also a range of women who are targeted by or whose situations are described by the websites. These overlap but include:

- all women;

- women in a particular country, region or continent;

- ethnic minority women (e.g. Hispanic, Latino, Filipino, Afghan, Maori, Native American, Jewish, Romany);

- refugee women;

- (in)migrant women;

- rural women;

- women in conflict zones [36];

- women in the military;

- women in particular sectors of employment or in the labour market generally;

- women suffering domestic violence;

- women in prison;

- women who are raped;

- deaf women;

- women with disabilities;

- prostitutes [37];

- older women;

- lesbians.

\section{Countries and Regions Covered}

Most of the world was covered but not to the same extent. Nevertheless, the coverage was sufficient to allow cross-national comparisons to be made.

- General: the 'Third World', all women, Europe, Latin America as a whole, South-east Asia, the Caribbean, Africa south of the Sahara;

- European countries: Austria, Belarus, Belgium, Bosnia, Denmark, England, Finland, France, Germany, Hungary, Ireland, the Netherlands, Norway, Portugal, Romania, Russia, Scotland, Slovenia, Sweden, Switzerland, the United Kingdom, Yugoslavia (Kosovo), Yugoslavia (Serbia);

- North America: the USA as a whole and different states; Canada;

- South and Central America: Belize, Chile, Nicaragua, Peru;

- Asia, Asia Minor: Afghanistan, Cambodia, China, Israel, Indonesia, Iran, Japan, Jordan, Malaysia, Palestine, Singapore, South Korea, Thailand;

- Oceania: Australia, New Zealand, Papua New Guinea;

- Africa: Algeria, Botswana, Congo, Egypt, Ethiopia, Kenya, Liberia, Morocco, Nigeria, Rwanda, Tanzania, South Africa, Swaziland, Uganda;

- Indian subcontinent: Bangladesh, India, Pakistan, Sri Lanka.

\section{The Situation in 2007}

In January 2007 exactly the same terms were input. This time 'women and the Internet' gave 20,500 pages (723 displayed); 'violence against women' gave 1,140,000 pages (798 displayed); and the terms 'women', 'sex', 'violence' yielded around 5,170,00 (809 displayed). The figures for pages displayed exclude those deemed by Google to be similar to its first display.

Of the three categories, only sites including 'women', 'sex' and 'violence' have increased in number. The first 755 sites were non-pornographic. The remainder, with just four intermingled exceptions, were sex sites. In all, then, the number of potentially educational sites in English 
yielded by using the search terms 'violence against women' and women + sex + violence has increased from 1,517 in 2001 to 1,557, a very small increase compared with the growth of the Web or indeed of the global population. On the other hand, the number of French sites yielded by 'violence contre les femmes' has increased to 344,000 , but only 564 were displayed, fewer than in 2001.

Some of the sites accessed in 2001 had disappeared by 2007, or had changed their role, their address or their contents.

According to the latest figures available, Internet usage still varies widely across the world, as Table VI shows. Notably, the world regions with the greatest percentages of Internet users are still Europe, Oceania and North America, which together account for just over half of world usage although they make up only $18 \%$ of the world's population. At the other end of the scale lies Africa, with very low usage rates and only $3 \%$ of world usage despite containing $14 \%$ of the world's population (Internet World Stats, 2006). Growth there is the highest in the world but has a long way to go to catch up with other developing regions.

\begin{tabular}{lcccc}
\hline World region & $\begin{array}{c}\text { No. of users } \\
\text { (approx. mil) }\end{array}$ & \% penetration & $\begin{array}{c}\text { Usage as \% of } \\
\text { world usage }\end{array}$ & $\begin{array}{c}\text { \% Increase } \\
2000-2006\end{array}$ \\
\hline Asia & 388 & 10.60 & 35.50 & 239.10 \\
Europe & 313 & 38.70 & 28.60 & 197.60 \\
N America & 232 & 70.00 & 21.30 & 114.70 \\
Latin America/Caribbean & 89 & 16.00 & 8.10 & 391.30 \\
Africa & 33 & 3.60 & 3.00 & 625.80 \\
Middle East & 19 & 10.20 & 1.80 & 490.10 \\
Australia/Oceania & 18 & 54.30 & 1.70 & 141.90 \\
World total & 1092 & 16.80 & & 202.40 \\
\hline
\end{tabular}

Table VI. World Internet usage at 1 December 2006. Source: Internet World Stats (2006).

It is still not possible, however, to give an accurate estimate of how many Web users are women, especially in developing countries, and existing data are unreliable (Stewart 2002; Hafkin, 2003; Dholakia et al, 2003). One exception is Korea where quarterly surveys of Internet use disaggregated by sex have been conducted and published since 2001. The Ministry of Gender Equality developed an 'informatisation' index, based on awareness, skills and effect, where women scored very highly, and usage and access, where they reported only a quarter as much as men. This gave women an overall score equivalent to $88 \%$ of that of men. Variation among women was based principally on age and income (Hafkin 2003).

Notwithstanding the overall relative paucity of data, Dholakia et al (2003) advance several useful points. First, apart from the USA and Canada, men are still the majority of Internet users, even though female participation has greatly increased in, for example, Mexico and Brazil. Second, there is in general a direct relationship between per capita income and the proportion of female Internet users. Third, women's per capita gross domestic product (GDP) is below that of men worldwide and the proportion varies across the world. Fourth, women are more likely to access the Internet in countries with a longer history of usage, such as Sweden and the United Kingdom, as opposed to Italy and Spain. Fifth, even where the Internet can be accessed cheaply in public venues, cultural barriers may dissuade or prevent women from taking up the opportunity. Sixth, basic computer skills are necessary and in many cases English language skills, although this situation is changing and the Web now hosts a much wider range of languages.

Stewart (2002) makes additional points. Access to and training in computers is most readily available through paid work, and women are less likely than men to be in the formal labour market and, where they are employed, more likely to undertake low-paid work. Furthermore, many people are employed by small and medium sized enterprises (SMEs) and these have been much slower than large organisations to adopt computerisation (Stewart, 2002).

In many developing countries, however, the majority of owners of SMEs are women entrepreneurs, and a few have benefited from information and communications technology (ICT) to generate foreign customers; and the outsourcing of many services has led to female employment in ICT industries, especially in Asia. On the other hand, women have less access to basic education, 
let alone training in computer literacy and foreign languages, less access to finance, and are more likely to live in rural areas with reduced access to ICT (UNCTAD 2002).

One way of approaching the question of women's access, then, is to take into account their lower levels of education and literacy and higher levels of poverty and marginalisation. These militate against their participation even when the physical infrastructure for Web access exists in an area. Thus, the lower a region's Gender Development Index [38], the more unequal Web access is likely to be. The country with the highest index in 2001, indicating the least inequality, was Norway (0.941). The 15 countries with the lowest indices (ranging from the Gambia with 0.457 to Niger with 0.279) are all in Africa (United Nations Development Programme [UNDP], 2003).

Even where inequality is low, however, other factors influence Internet use, including age. A study of the European Union found that the narrowest gender gap was in the 16-24 age group (Ottens [2004], and see Hafkin [2003] for similar findings from the Korean surveys). One interesting finding, worthy of further exploration, was that the smallest gender gap was found in Finland, Estonia, Lithuania and Latvia (Ottens, 2004), although these rank 14th, 41st, 45th and 50th respectively out of the 175 countries on the Gender Development Index (UNDP, 2003).

\section{Conclusions}

The debate on globalisation includes questions like (a) whether it is really a new state of affairs or merely a continuation of earlier developments such as the telegraph, long-distance trade and colonisation; (b) whether the effect of global media such as the Web is broadly positive or negative; and (c) whether in any case unequal access to the Internet does not undermine the potential of the Web.

Leaving aside question (a) as lying considerably beyond the scope of this article and taking up question (b), many misgivings have been expressed about the content of the World Wide Web and its accessibility to people of any age and any tendency. A small but significant proportion of the content is, apparently, pornographic and this includes not only women as sexual partners but also women as subjects and objects of violence. Pornographic sites generate a large amount of web traffic. Another aspect of the Web is the large amount of information, but also misinformation, unsupported opinion, school children's simple projects and so on, found on the millions of home pages kept by individuals.

What this search revealed, however, is the potential of the Web for educating, informing and supporting women who have suffered violence as well as those with other interests in the topic, such as social and legal theorists. This potential is being realised to an impressive degree in countries such as the USA and Canada.

Furthermore, women from all walks of life and parts of the world are represented on the Web, either by themselves or by others who are concerned for their welfare and who publicise the plight of women whose voices are largely unheard and who do not themselves have access to the Internet. The Web also offers the possibility for women from different parts of the world to communicate, to exchange experiences, discover similarities and form bonds, initiate joint actions and transfer ideas.

Going to question (c), with the decreasing price of computer technology and the greater availability of Internet access, through net bars or Internet cafes, offices, schools, colleges and universities, more people can access the Web than may be realised, and often relatively cheaply. In very poor countries, where electricity and even water are scarce, and life for many consists of a struggle for basic survival, it is still only the elite who have this access - but this elite includes people with the power to effect change if they so choose.

One interesting example of Web access in rural areas is Kerala's e-literacy campaign, which aims to assist every household to have one member who can use a computer in addition to all school children (in the only part of India where almost all children attend school). Piloted in one district, Malappuram, where the request for such a facility came from the grass roots, that is, poor Muslim families with relatives working in the Gulf, it is now being extended to the rest of the state. In many centres the majority of students are women. Although email is the main activity, the main newspaper in the state, Malayala Manorama, has found a big increase in visits to its online edition.[39] 
International bodies like the United Nations and its agencies also use their influence to try to effect change. The raped women of war zones may not be able to speak for themselves, but organisations, from local grass-roots associations up to national governments, can and do speak for them, publicise their plight and generate national and international laws which, even if not obeyed, at least give a space for justice to prevail.

Finally, to return to the issues for adult education, using the Web for self-directed adult education carries similar disadvantages to learning through adult education providers. Access and participation are reduced for the least advantaged, through lack of time and money to access the Internet. For those with such access, good search skills are required to find out what exists and informed critical skills to assess the quality of provision, in an environment where many sites of varying quality exist. Useful websites sometimes disappear, change their names or drop some of their content (or make it hard to find), just as adult education providers drop or change courses or cease existence (viz. the disappearance of university extramural departments in much of England). There are also problems not associated with conventional adult education, such as the impact of viruses, spam email, abusive messages and the health and safety issues arising from computer use.

On the other hand, there are distinct advantages. The Web contains a great quantity and very wide range of resources, giving self-directed learners the opportunity to tailor their own 'courses', define their own learning aims and organise their own time. It is possible to form online learning groups or simply make contact with like-minded individuals who provide support and information. Such contacts can be global, providing insights into other countries and cultures. It does not even demand active participation by its users, who can lurk unseen. Those who wish to contribute their own experiences and insights may do so, through both specialised message boards and chat rooms and through the Web 2.0 sites where content is generated by users. The amount of material on women and violence is quite large and covers a wide spectrum of issues. The 2007 Google search found a greater number of academic papers than in 2001. The quality of such material is variable but the contribution of higher education institutions, if not a guarantee of quality, at least offers some kind of reassurance.

Access to and participation in face-to-face adult education are problematic for many people and the need for electronic access to web-based material imposes a financial burden that is too great for the majority of women in the world to circumvent. At the same time, however, the price of such access is falling and it should not be forgotten that the Internet can and does link people living in remote or isolated areas. As for participation, in the sense of women using the Web for learning about women and violence, the potential is there but we need much more evidence about the numbers of women who access the Web for such educational purposes as well as for email and shopping.

Nevertheless, if the Web excludes those without financial resources or physical access, it includes the disabled, the shy, the exam-phobic, the busy, the travellers, the housebound and others who find it difficult to attend regular face-to-face classes or prefer not to take formallyassessed courses.

\section{Notes}

[1] Understandably, the University of Glasgow has a strict policy on staff using its resources to indulge in pornography, so before beginning the search, the webmaster was informed of the possibility of pornographic sites being accessed by accident. In the event, this did not happen.

[2] For world figures, see http:/ / www.internetworldstats.com/stats.htm - the original provider of this information, http: / / www.nua.ie, seems no longer to conduct or disseminate surveys.

[3] In the first 100 pages, 69 were entirely from the USA; 11 were based in Canada, 6 in the United Kingdom, 4 in Switzerland (of which 2 were in partnership with the USA), 2 each in Ireland and Australia, 1 each in Germany, Belgium, Belarus, Denmark and Colombia; and 1 is on a United Nations site.

[4] 'Content Intelligence: women more likely to be frequent Net users'. http: / / www.nua.ie/surveys/index.cgi?f=FS\&cat_id=35 [no longer functional].

[5] Note that Hafkin (2003) states that the figure of $38 \%$ female Internet use in Zambia is very dubious but often quoted. 
[6] For example, http:/ / www-sul.stanford.edu/depts/ssrg/africa/women.html (annotated guide to online resources on women in sub-Saharan Africa, including sites for women in Ghana, Kenya, Ethiopia, Senegal, South Africa, Cameroon, Tanzania, Mozambique and Nigeria).

[7] Web pages linking to sites of international interest include the following: http: / / www.library.wisc.edu/libraries/WomensStudies/fc/fchelga.htm (includes women's web resources in Germany, Austria and many other countries) and http:/ / www.gender.iatp.unibel.by [no longer functional] (included useful European sites as well as others).

[8] Articles and analyses concerning women's Internet use were found at, for example: http:/ / www.connected.org/women/women.html; http:/ / www.connected.org/women/sally.html [no longer functional]; http: / / www2000.ogsm.vanderbilt.edu/Student.Projects / Women/conventional_wisdom.html; http:/ / www.well.com/ user/freedom/internet.html [no longer functional].

[9] http: / /www.herplace.org (Canadian Women's Internet Association 'to give all women both a voice and a place of their own in Cyberspace').

[10] http:/ / www.igc.org/igc/gateway/wnindex.html [no longer functional] (WomensNet 'supports women's organisations locally, nationally and worldwide'. Part of IGC Internet, with PeaceNet, EcoNet and AntiRacismNet); http: / /www.womenspace.ca (Women's Internet Campaign: site map); http: / www.ohio-usa.com/women ('Women of the Undernet: a unique organization dedicated to mobilizing women over the Internet, empowering women politically and stopping the anti-women agenda of the Radical Right').

[11] http:/ / www.leeds.gov.uk/lcc/equalops/eq_liap.html [no longer functional] (Leeds Social Services Department Interagency Project on Women and Violence).

[12] For example, http:/ / www.who.int/violence_injury_prevention/vaw/infopack.htm [no longer functional] (World Health Organisation Violence Against Women Information Pack).

[13] For example, http:/ / www.un.org/rights/dpi1772e.htm (United Nations); http: / / europa.eu.int/comm/employment_social/equ_opp/redirect.html [no longer functional] (European Commission, DG Employment and Social Affairs, Anti-violence campaign site).

[14] For example, http:/ / www.now.org/issues/violence (National Organisation for Women).

[15] For example, http:/ / www.ittijah.org/womenagainst.htm [no longer functional] (Women Against Violence - group of Arab women).

[16] For example, http:/ / www.thebody.com/iapac/violence-women.html (Ninth International Nursing Conference on Ending Violence Against Women).

[17] For example, http:/ / www.wave-network.org (Women Against Violence Europe).

[18] For example, http:/ / www.cwlc.org (California Women’s Law Center).

[19] For example, http:/ / www.wavaw.ca [no longer functional] (Women Against Violence Against Women); http://www.deptford.org.uk/Community_Services/domvince.html [no longer functional] (Women Against Domestic Violence).

[20] For example, http:/ / www.thesafetyzone.org/links/ index.html [no longer functional] (Domestic Violence Web Links); http:/ / www.home.cybergrrl.com/dv [no longer functional] (Cybergrrl Violence Resources for Women).

[21] For example, http://www.emich.edu/public/wstudies/cwv.html [no longer functional] (Commission on Women and Violence).

[22] For example, http: / / www.library.wisc.edu/libraries/WomensStudies/core/ crlaw [no longer functional] (Review of Applications of Feminist Legal Theory to Women's Lives: Sex, Violence, Work and Reproduction); http: / /www.designcommunity.com/law/womens_law.html (Women's Law Resources).

[23] For example, http:/ / www.tompaine.com/news/2001/06/22/1.html [no longer functional] (how the Media Cover Women).

[24] For example, http:/ / www.feminist.org/gateway/vs_exec2.html [no longer functional] (Feminist Majority Foundation).

[25] For example, http:/ / www.mincava.umn.edu/bibs/samesex.htm (Same-Sex Domestic Violence Bibliography). 
[26] For example, http:/ / www.un.org/womenwatch/daw/beijing/platform/violence.htm (Violence Against Women).

[27] For example, http:/ / www.homeoffice.gov.uk/domesticviolence [no longer functional] (United Kingdom Home Office Agenda on Violence against Women);

http:/ / usinfo.state.gov/topical/global/women/violence.htm [no longer functional] (Women and Violence: United Nations policy paper).

[28] For example, http:/ / www.silcom.com/ paladin/madv [no longer functional] (Internet-based coalition of men and women working to address the issue of domestic violence).

[29] For example, http:/ / www.nwjc.org.au (National Women's Justice Coalition).

[30] For example, http:/ / www.weaveincorp.org (Women Empowered Against Violence); http:/ / members.tripod.com/wsfrc (Women's Service and Family Resource Center); http:/ / www.saltspring.com/swova (Saltspring Women Opposed to Violence and Abuse); http:/ / www.wdvh.org.uk/helpline.htm (Women's Domestic Violence Helpline).

[31] For example, http:/ / www.osw.dpmc.gov.au/content/rural/ruralwom.htm [no longer functional] (Rural Women Domestic Violence Kit).

[32] For example, http: / www.wagv.org (Women Against Gun Violence).

[33] For example, http:/ / www.glow-boell.de/home/content/d/dates/2001/10/kurdistan/render_doc

[34] See http:/ /icg.harvard.edu/ ws131 [no longer functional] (Women, Violence and the Law by Diane L. Rosenfeld).

[35] For example, http:/ / www.women.com/sex/forums/couples/monogame/F1004 [no longer functional] (Women.com - Bureau of Justice Statistics).

[36] For example, http: / www.hrw.org/campaigns/women/icty and http:/ / www.hrw.org/women (Human Rights Watch).

[37] For example, http:/ / www.uri.edu/artsci/wms/hughes/catw/khnwsa.htm [no longer functional] ('Pimps, Tricks and Feminists'); http:/ / www.twnside.org.sg/title/millions.htm ('Modern Slavery forcing millions of women into the sex industry').

[38] 'A composite index measuring average achievement in the three basic dimensions captured in the human development index - a long and healthy life, knowledge and a decent standard of living adjusted to account for inequalities between men and women'. http:/ /hdr.undp.org/reports/global/2003/indicator/indic_197_1_1.html

[39] This was the subject of a recent research visit to Kerala by the author and will be published in the near future.

\section{References}

Clayton, P. (2002) La violence contre les femmes et Internet, Le Fil d'Ariane, Cahiers du Centre d'études des mutations en Europe. Paris: Institut d'études européennes.

Dholakia, R.R., Dholakia, N. \& Kshetri, N. (2003) Gender and Internet Usage, prepared for The Internet Encyclopedia, edited by Hossein Bidgoli. New York: Wiley. http: / / ritim.cba.uri.edu/wp2003/pdf_format/Wiley-Encycl-Internet-Usage-Gender-Final.pdf

Hafkin, N.J. (2003) Some Thoughts on Gender and Telecommunications/ICT Statistics and Indicators. Paper presented at ITU World Telecommunication/ICT Indicators Meeting, Geneva, Switzerland, 15-17 January. http:/ / www.itu.int/ITU-D/pdf/ 5196-007-en.pdf

Internet World Stats (2006) Internet Usage Statistics: the big picture - world Internet users and population stats. http:/ / www.internetworldstats.com/stats.htm

Ottens, M (2004) Internet Usage by Individuals and Enterprises 2004. http: / / epp.eurostat.cec.eu.int/cache/ITY_OFFPUB/KS-NP-05-018/EN/KS-NP-05-018-EN.PDF

Stewart, James (2002) Information Society, the Internet and Gender: a summary of pan-European statistical data. http: / / www.rcss.ed.ac.uk/sigis/public/D02/D02_Part2.pdf

United Nations Conference on Trade and Development (UNCTAD) (2002) E-commerce and Development Report 2002. http://r0.unctad.org/ecommerce/docs/edr02_en/ecdr02ch3.pdf

United Nations Development Programme (UNDP) (2003) Human Development Indicators 2003: genderrelated development index. http://hdr.undp.org/reports/global/2003/indicator/indic_197_1_1.html 
PAMELA CLAYTON is a Research Fellow in the Department of Adult and Continuing Education, University of Glasgow. Her research interests include vocational guidance, adult learning and literacy, and social exclusion. Correspondence: Dr Pamela Clayton, Department of Adult and Continuing Education, University of Glasgow, St Andrew’s Building, 11 Eldon Street, Glasgow G3 6NH, United Kingdom (p.clayton@educ.gla.ac.uk). 